learned so much during the young man's adolescence. I enjoyed the interchange and we both laughed.

I am not a researcher, not a technically minded clinician. I could never emulate Max but I admired him as much as any mentor. I think the reason for this can be summed up in his humanity and sensitivity, which not everyone, I think, was privileged to see. He

At an international symposium held at The Friends Hospital, Philadelphia, on 17 and 18 October 1988, to celebrate the 50th Anniversary of the first ECT, a combined these qualities with enormous academic, clinical and professional achievement.

Max, you gave us a tremendous amount. Some of us wanted more. I am grateful for my generous share. Thank you for everything.

Now relax.

DPF

moving tribute to 'Max' was paid by Professor Max Fink.

\title{
Miscellany
}

\section{Policy Studies Institute 10th anniversary}

The Policy Studies Institute is an independent research organisation undertaking studies of economic, industrial and social policy and the workings of political institutions. PSI was formed in 1978 by merger between Political and Economic Planning, established 1930, and the Centre for Studies in Social Policy (CSSP), established 1973. It publishes between 30 and 40 books and reports each year and recent publications have included Doctors and their Careers, which highlights the way that the skills and talents of women doctors are wasted; and Illicit Drug Use, which underlines the links between alcohol abuse, under-age smoking and illicit drug abuse. Further information: PSI, 100 Park Village East, London NW1 3SR.

\section{Dr Bertram Mandelbrote}

Dr Mandelbrote has retired after nearly 30 years service to Phoenix Unit, Littlemore Hospital and the Oxford Area.

\section{Diploma in Family Therapy}

The Department of Psychiatry, University of Manchester, will be holding a part-time course extending over a two year period beginning in late September 1989. Attendance is on one day per week during each academic term. The teaching focuses upon the theory and practice of family therapy. Further details: Dr Michael Kerfoot, University of
Manchester, Department of Psychiatry, Williamson Building, Oxford Road, Manchester M13 9PL (telephone 061-275 2000).

\section{New publication}

Mental Handicap and Mental Health: A Community Service

by Nick Bouras, Katie Drummond, David Brooks and Matt Laws, is a research report describing five years of detailed monitoring of clinical activities, service developments and future challenges from the National Unit for Psychiatric Research and Development. Copies are available from NURPD, Lewisham Hospital, London SE13 6LH, price $f 5$ (including postage and packing); cheques should be made payable to NURPD.

\section{Dr Frank J. Ayd, Jr}

Dr Ayd, an Affiliate of the College, was awarded the Open Mind Award in Psychiatry recently by Queen Fabiola of Belgium at the close of an international scientific symposium on drugs for emotional and mental disorders. Dr Ayd is Emeritus Director of Professional Education and Research at Taylor Manor Hospital, Ellicott City, Maryland, USA and Clinical Professor of Psychiatry, West Virginia University Medical Center-Charleston. The two other recipients of the Award were Dr Pierre Deniker of France and Dr Paul Janssen of Belgium. 